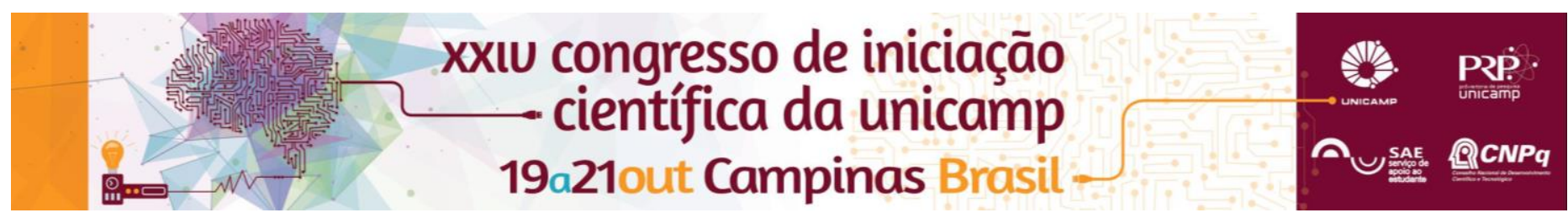

\title{
APLICAÇÃo DE RESÍDUOS CERÂMICOS NA FABRICAÇÃO DE PEÇAS DE CONCRETO PARA PAVIMENTAÇÃO.
}

\section{Rafaela do Amarante Carneiro1; Gisleiva C.S. Ferreira2; Sandra Maria Cardoso3; Wélida de Sousa Sarro4}

1 Aluna de Iniciação Científica - SAE; 2 Profa. Dra. Orientadora; 3 Mestranda - FT; 4 Graduanda - FT.

\section{Resumo}

A preocupação com o meio ambiente deve ser uma ação mundial por parte de todos os segmentos da sociedade. Atualmente, a construção civil é responsável por quase $50 \%$ do volume de resíduos sólidos gerados. O objetivo desta pesquisa foi verificar o desempenho mecânico de peças de concreto para pavimentação (pavers) com substituição parcial do agregado por resíduo cerâmico. Após definição dos teores de substituição, foram moldados pavers conforme NBR 9781:2013. Conforme características do lote do resíduo e traço adotado, é viável fabricar pavers com até 50\% de substituição, considerando o comportamento mecânico descrito na norma citada.

Palavras-chave: passivo ambiental, resíduos sólidos, agregado reciclado.

\section{Introdução}

A utilização dos resíduos da construção e demolição (RCD) mostra-se como uma ótima opção de reciclagem, redução de custos e de consumo de recursos naturais (JOHN, 2000). Neste sentido, definiu-se a seguinte metodologia:

- triagem, moagem e caracterização do resíduo cerâmico (figuras 1 e 2);

- moldagem dos pavers;

- resistência à compressão dos pavers conforme NBR 9781:2013.
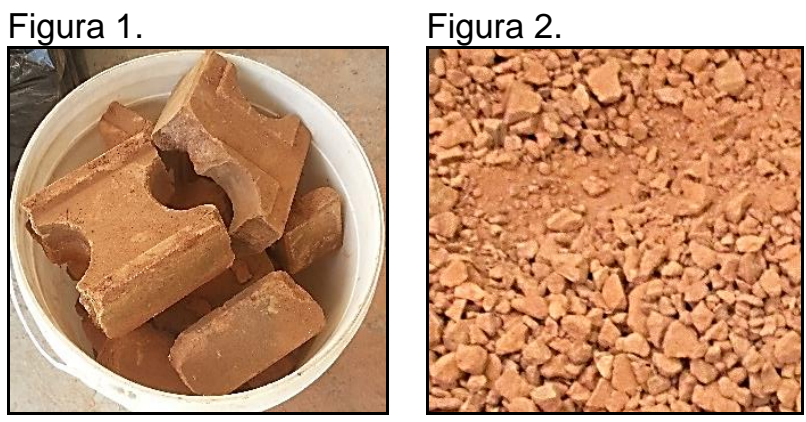

$\mathrm{Na}$ tabela 1 estão dispostos as quantidades $(\mathrm{kg}) \mathrm{de}$ materiais utilizados para a moldagem de 8 pavers para cada teor de resíduo cerâmico ( $20 \%$ e $50 \%)$.

Tabela 1. Materiais utilizados na moldagem dos pavers.

\begin{tabular}{lccc}
\hline Materiais $(\mathrm{kg})$ & \multicolumn{3}{c}{ Traço } \\
\cline { 2 - 4 } & $0 \%$ & $20 \%$ & $50 \%$ \\
\hline Pó de pedra & 19,6 & 16 & 5,6 \\
Cimento & 8 & 8 & 8 \\
Res. cerâmico & - & 4 & 14 \\
Pedrisco & 8,4 & 4 & 5,6 \\
Areia & - & 4 & 2,8 \\
Aditivo $\left(\mathrm{cm}^{3}\right)$ & 24 & 24 & 24 \\
Água & 2,4 & 2,56 & 2,4 \\
\hline
\end{tabular}

Resultados e Discussão

Figura 3. Resistência à compressão média dos pavers.

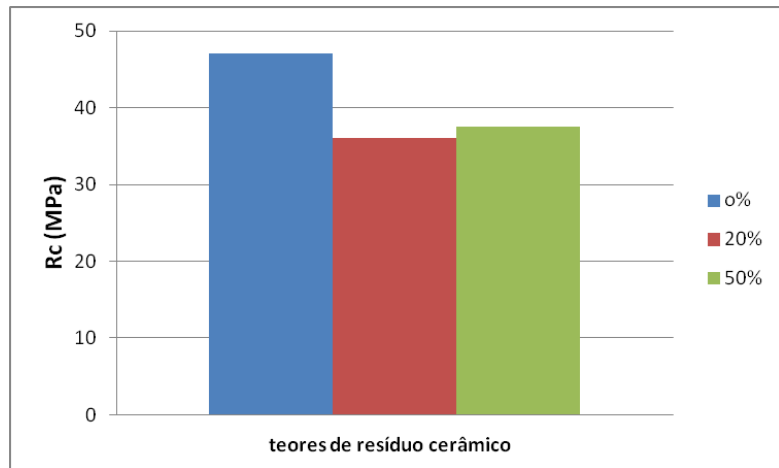

A tabela 2. Caracterização física do resíduo cerâmico.

\begin{tabular}{lcc}
\hline Ensaio & $\mathrm{DM}^{*}(\mathrm{~mm})$ & $\mathrm{MF}^{* *}$ \\
\hline Granulometria & 19 & 5,69 \\
& (graúdo) & (miúdo) \\
M. esp. $\left(\mathrm{kg} / \mathrm{m}^{3}\right)$ & 1,82 & 2,72 \\
M. esp. ap. $\left(\mathrm{kg} / \mathrm{m}^{3}\right)$ & 2,21 & 2,25 \\
M. unitária $\left(\mathrm{kg} / \mathrm{m}^{3}\right)$ & 927 & 911 \\
Absorção água $(\%)$ & 18,2 & 17,2 \\
\hline
\end{tabular}

*DM: diâmetro máximo

**MF: módulo de finura

\section{Conclusões}

Apesar da redução na resistência à compressão dos pavers com resíduo cerâmico, os dois teores apresentaram valores superiores ao mínimo exigido por norma $\left(F_{c k}=35 \mathrm{MPa}\right)$.

\section{Agradecimentos}

FT e SAE - UNICAMP; Prefeitura Municipal de Limeira, SP.

NBR 9781 - Peças de concreto para pavimentação Determinação da resistência à compressão - Método de ensaio. Rio de Janeiro. 2013

JOHN, V.M. Reciclagem de resíduos na construção civil contribuição a metodologia de pesquisa e desenvolvimento. 2000. 102 p. Tese (livre docência) - Escola Politécnica da Universidade de São Paulo, São Paulo, 2000. 